OPEN ACCESS

Edited by:

Issy Laher,

University of British Columbia,

Canada

Reviewed by:

Rolf Teschke,

Hospital Hanau, Germany

Wenchuan Bi,

Shenzhen University, China

${ }^{*}$ Correspondence:

Xuanbin Wang

wangxb@hbmu.edu.cn

Fengjun Cao

fengjuncao@hbmu.edu.cn

Specialty section: This article was submitted to

Ethnopharmacology,

a section of the journal

Frontiers in Pharmacology

Received: 01 April 2019

Accepted: 22 July 2019

Published: 05 September 2019

Citation:

Ding Y, LiU YC, Li H, Li Y, Li M, LiU M, Wang XH, Cao F and Wang XB (2019) Chinese Medicines for Preventing and Treating Radiation-Induced Pulmonary Injury: Still a Long Way to Go.

Front. Pharmacol. 10:927.

doi: 10.3389/fphar.2019.00927

\section{Chinese Medicines for Preventing and Treating Radiation-Induced Pulmonary Injury: Still a Long Way to Go}

\author{
Yan Ding ${ }^{1}$, Yuechao Liu ${ }^{1}$, Hongliang $L^{1}{ }^{1}$, Yong $L^{1}{ }^{1}$, Minglun $L^{2}{ }^{2}$, Ming Liu ${ }^{1}$, Xianhe Wang ${ }^{1}$, \\ Fengjun $\mathrm{CaO}^{1 *}$ and Xuanbin Wang ${ }^{1,3 *}$
}

\begin{abstract}
${ }^{1}$ Laboratory of Chinese Herbal Pharmacology, Oncology Center, Renmin Hospital, Hubei University of Medicine, Shiyan, China, ${ }^{2}$ Department of Radiation Oncology, University Hospital, LMU, Munich, Germany, ${ }^{3}$ Biomedical Research Institute, Hubei Key Laboratory of Wudang Local Chinese Medicine Research, Hubei University of Medicine, Shiyan, China
\end{abstract}

Thoracic radiotherapy is a mainstay of the treatment for lung, esophageal, and breast cancers. Radiation-induced pulmonary injury (RIPI) is a common side effect of thoracic radiotherapy, which may limit the radiotherapy dose and compromise the treatment results. However, the current strategies for RIPI are not satisfactory and may induce other side effects. Chinese medicines (CMs) have been used for more than a thousand years to treat a wide range of diseases, including lung disorders. In this review, we screened the literature from 2007 to 2017 in different online databases, including China National Knowledge Infrastructure (CNKI), Chongqing VIP, Wanfang, and PubMed; summarized the effectiveness of $\mathrm{CMs}$ in preventing and treating RIPI; explored the most frequently used drugs; and aimed to provide insights into potential CMs for RIPI. Altogether, CMs attenuated the risk of RIPI with an occurrence rate of $11.37 \%$ vs. $27.78 \%(P<0.001)$ compared with the control groups. We also found that CMs (alone and combined with Western medical treatment) for treating RIPI exerted a higher efficacy rate than that of the control groups $(78.33 \% \mathrm{vs}$. $28.09 \%, P<0.001)$. In the screened literature, $38 \mathrm{CMs}$ were used for the prevention and treatment of RIPI. The top five most frequently used CMs were Astragali Radix (with a frequency of $8.47 \%$ ), Ophiopogonis Radix (with a frequency of $6.78 \%$ ), Glycyrrhizae Radix et Rhizome (with a frequency of 5.08\%), Paeoniae Radix Rubra (with a frequency of 5.08\%), and Prunellae Spica (with a frequency of 5.08\%). However, further high-quality investigations in CM source, pharmacological effects and underlying mechanisms, toxicological aspects, and ethical issues are warranted. Taken together, CMs might have a potential role in RIPI prevention and treatment and still have a long way to investigate.

Keywords: Chinese medicines, radiation-induced pulmonary injury, prevention, treatment, tonics, review

\section{INTRODUCTION}

Thoracic radiotherapy is a mainstay of treatment for patients who have cancer, e.g., lung cancer, esophageal cancer, and breast cancer. Radiation-induced pulmonary injury (RIPI) is a common side effect, including two phases, acute radiation pneumonitis and chronic radiation-induced pulmonary fibrosis (Cao et al., 2017; Huang et al., 2017). The symptoms include a dry cough, shortness of breath, chest pain, fever, and even severe respiratory failure and death (Huang et al., 
2017). RIPI is highly likely to occur with a high dose and dose rate of radiation. Capillary endothelial and type I cells (epithelial lining cells) appear to be most susceptible to RIPI (Abid et al., 2001). RIPI may lead to a reduction and damage in pulmonary function, which involves a cascade of inflammatory events, including oxidative damage (Demirel et al., 2016), sphingomyelin hydrolysis, and apoptotic DNA degradation (Abid et al., 2001). Patients with RIPI typically suffer from dyspnea with a decreased vital capacity (VC), forced vital capacity (FVC), forced expiratory volume in $1 \mathrm{~s}$ (FEV1), alveolar volume $\left(\mathrm{V}_{\mathrm{A}}\right)$, transfer factor of carbon monoxide $\left(\mathrm{T}_{\mathrm{L}, \mathrm{CO}}\right)$, and residual volume $(\mathrm{RV})$ (Enache et al., 2013). On the cellular and molecular level, radiation may result in damage to the alveolar epithelial cells as well as vascular endothelial cells and the secretion of a large number of proinflammatory and pro-fibrotic cytokines, including transforming growth factor (TGF)- $\beta 1$, interleukin-13 (IL-13), endothelin-1 (ET-1), platelet-derived growth factor (PDGF), cyclooxygenase (COX), and prostaglandin E2 (PGE2). Furthermore, type 1 helper T cells (Th1 cells) may affect RIPI by secreting IL-4 and IL-13, while type 2 helper T cells (Th2 cells) induce collagen synthesis for tissue remodeling and fibrosis (Huang et al., 2017). To date, the treatment strategies for RIPI are mainly based on glucocorticoids, angiotensin-converting enzyme inhibitors (ACEIs), and pentoxyphylline (Deng et al., 2017). Thus, a comprehensive review of the effects of CMs on RIPI may help discover the most effective CMs. In this review, studies of CMs in RIPI were retrieved from online databases from 2007 to 2017. The literature was screened using the inclusive and exclusive criteria and analyzed using statistical software.

\section{MATERIALS AND METHODS}

\section{Data Retrieval and Collection}

The keywords "radiation-induced pulmonary/lung injury, "radiation-induced pneumonitis/pulmonary fibrosis, and "Chinese medicine/ traditional Chinese medicine/ Chinese herbal medicine" were used to retrieve studies of CMs in RIPI from 2007 to 2017 from the online databases of China National Knowledge Infrastructure (CNKI), Chongqing VIP, Wangfang, and PubMed. The duplicates were discarded. The overall efficacy, changes of pulmonary function, underlying mechanisms, CM species and families, traditional use, and usage frequency in these studies were summarized and analyzed. The study was approved by the Ethical Commitee of Hubei University of Medicine.

\section{Criteria of Inclusion}

The inclusion criteria were as follows:

- The contents of the literature involved the clinical effects of CMs on RIPI, including radiation-induced pneumonitis and/ or pulmonary fibrosis.

- The references included pure compounds, fractions, and formulae of CMs. The CMs were composed of fungi, plants, animals, and their parts, and minerals.

- The design of the studies was randomized and controlled.

- The studies described some parameter of lung function.

\section{Criteria of Exclusion}

The data from the following literature were excluded:

- The literature was associated with neither CMs nor RIPI.

- The pure compounds were not naturally from CMs but were chemical derivatives.

- The species of CMs were not given or could not be determined.

- The fractions and/or formulae of CMs were described without the extraction methodology.

- The components of the formulae were not given.

- The manufacturer and/or manufacturing data were not stated if marketed CM preparations were used.

- The dosage of the drugs was not given.

- Only the overall efficacy of CMs on RIPI was described without any assessment of lung function or biochemical indices.

- The studies were not randomized and controlled.

- The literature did not claim any ethical approvals, and the studies without desclaim of patients' agreement or signing informed consents.

- The study was any review or a meta-analysis.

\section{Statistical Analysis}

The data were selected based on the criteria defined in the inclusion and exclusion criteria for clinical settings, and they were summarized and analyzed using SPSS19.0 (SPSS Inc., Chicago, IL, USA) and GraphPad Prism 5.0 (GraphPad Software, Inc. La Jolla, CA, USA). Data were presented as the mean \pm standard deviation (SD). One-way ANOVA was performed for multiple comparisons analysis, and two-sided Student's $t$ test was used to compare differences between the two groups. $P<0.05$ was considered statistically significant.

\section{RESULTS}

\section{General Information on Literature Retrieval}

A total of 642 papers were retrieved, including 390 duplicates and irrelevant literature, 53 reviews and meta-analysis, and 191 articles that were excluded using the selection criteria. As a result, eight studies that met the selection criteria were summarized and analyzed (Figure 1). Ethics committees approved all clinical trials, and all patients agreed on participating studies and signed informed consents. The CMs examined in eight studies (five for prevention, one for treatment, and two for both) included eight formulae (Table 1). Furthermore, some CMs were used with a high frequency (Table 2). In these papers, the 883 patients were randomly divided into two groups, the control group (Ctrl, 407 patients), the CM-preventing group (CMs, 343 patients) (Figure 2), and the CM-treating group (CMs, 180 patients) (Figure 3).

\section{Effects of CMs on Preventing RIPI}

For the seven studies, the Ctrl groups (with a mean age of 59.5 years) were treated with radiotherapy only, while the CM groups received CM pre-intervention (with a mean age of 59.5 years) in addition to radiotherapy. The total RIPI occurrence rates in the Ctrl and the CM groups were $27.78 \%$ and $11.37 \%$, respectively $(P<0.001)$, indicating that CMs significantly attenuated the risk of RIPI (Figure 2). 


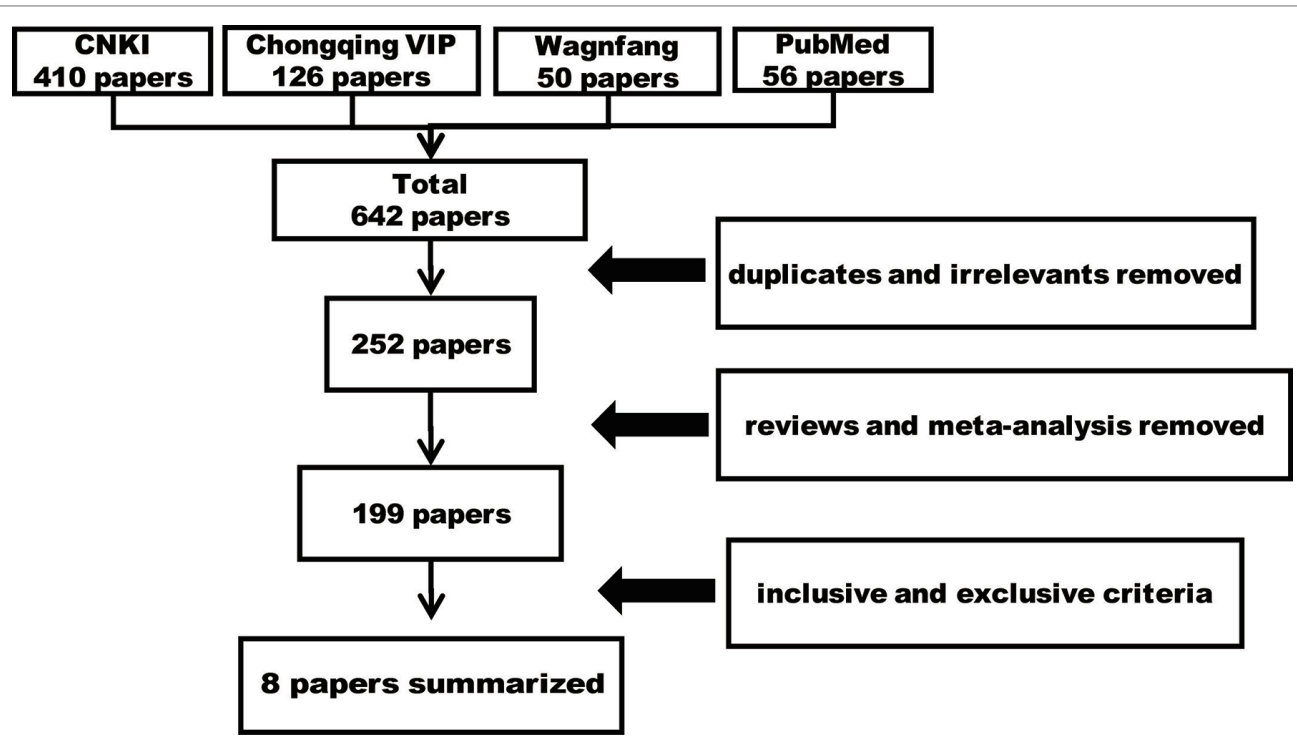

FIGURE 1 | The workflow of retrieving literature.

TABLE 1 | List of CMs formulae for RIPI.

\begin{tabular}{|c|c|c|c|c|c|}
\hline Name & Main components & Dose & Effect and mechanism & Stage & References \\
\hline $\begin{array}{l}\text { Qing Zao Jiu Fei } \\
\text { Decoction-1 }\end{array}$ & $\begin{array}{l}\text { Mori folium (9 g), Gypsum fibrosum ( } 8 \mathrm{~g}) \text {, Glycyrrhizae radix et } \\
\text { Rhizoma (3 g), Sesame ( } 3 \mathrm{~g}) \text {, Asini corii colla (3 g), Eriobotryae } \\
\text { folium (3 g), Ginseng radix et Rhizoma (2 g), Armeniacae Semen } \\
\text { Amarum (2 g), Ophiopogonis radix (4 g), Astragali radix (3 g) }\end{array}$ & $100 \mathrm{ml}$ & TGF- $\beta 1 \downarrow ; \mid l-1 \downarrow$ & $\mathrm{RIPI}$ & (Xia et al., 2010) \\
\hline $\begin{array}{l}\text { Qing Re Huo Xue San Jie } \\
\text { Fang }\end{array}$ & $\begin{array}{l}\text { Prunella spica (15 g), Cremastrae Pseudobulbs Pleiones } \\
\text { Pseudobulbus (15 g), Forsythiae Fructus (12 g), Astragali radixn } \\
\text { (125 g), Paeoniae radix rubra (10 g), Moutan cortex (10 g) }\end{array}$ & $100 \mathrm{ml}$ & $\begin{array}{l}\text { TNF- } \alpha \downarrow ; I L-1 \downarrow ; \text { TGF- } \beta 1 \\
\downarrow ; \text { MMP-9 } \downarrow\end{array}$ & RIPI & (Tu et al., 2015) \\
\hline Bu Qi Yang Yin Fang & $\begin{array}{l}\text { Rhodiola crenulate radix et Rhizoma (20 g), Astragali radix (20 g), } \\
\text { Lycii Fructus (15 g), Pseudostellariae radix (15 g), Ophiopogonis } \\
\text { radix (15 g), Eriobotryae folium (15 g), Angelicae Sinensis Radix } \\
\text { (15 g), Prunellae spica (10 g), Gypsum fibrosum (10 g), Curcumae } \\
\text { radix (10 g), Curcumae longae rhizoma (10 g) }\end{array}$ & $100 \mathrm{ml}$ & $\begin{array}{l}\text { VC } \uparrow ; \text { FVC } \uparrow ; \text { FEV } 1 \uparrow ; \\
\text { TGF- } \beta 1 \downarrow ; \text { TNF- } \alpha \downarrow\end{array}$ & $\mathrm{RIPI}$ & $\begin{array}{l}\text { (Zhou and Chen, } \\
\text { 2017) }\end{array}$ \\
\hline Qi Shen Yi Fei Decoction & $\begin{array}{l}\text { Astragali Radix (30 g), Codonopsis Radix (15 g), Ophiopogonis } \\
\text { Radix (15 g), Prunellae spica (15 g), Fritillariae cirrhosia bulbus } \\
\text { (12g), Forsythiae Fructus (12 g), Astragali Radix (12 g), Descurainiae } \\
\text { Semen lepidii Semen (10 g), Persicae semen (10 g), Moutan Cortex } \\
\text { (10 g), Salviae Miltiorrhizae Radix et Rhizoma (10 g), Paeoniae } \\
\text { Radix Rubra (10 g), Glycyrrhizae Radix et Rhizoma (6 g) }\end{array}$ & $100 \mathrm{ml}$ & $\begin{array}{l}\text { VC } \uparrow ; \text { FVC } \uparrow ; F E V 1 \uparrow ; I L-6 \\
\downarrow ; T N F-\alpha \downarrow ; T G F-\beta 1 \downarrow\end{array}$ & $\mathrm{RP}$ & (Shi et al., 2016) \\
\hline Qing Fei Decoction & $\begin{array}{l}\text { Rehmanniae Radix (12 g), Ophiopogonis Radix (9 g), Scrophulariae } \\
\text { Radix (9 g), Sheng Glycyrrhizae Radix et Rhizoma (3 g), Menthae } \\
\text { Haplocalycis Herba (3 g), Asteris Radix et Rhizoma (5 g), Moutan } \\
\text { Cortex (5 g), Paeoniae Radix Alba (5 g) }\end{array}$ & $100 \mathrm{ml}$ & $\| \mathrm{L}-1 \downarrow ; \mathrm{TNF}-\alpha \downarrow$ & $\mathrm{RIPI}$ & (Li et al., 2017) \\
\hline $\begin{array}{l}\text { Wu Wei Xiao Du Yin Jia } \\
\text { Jian Fang }\end{array}$ & $\begin{array}{l}\text { Lonicera Japonicae Flos (20 g), Viola Herba (15 g), Ford Nervilia Herb } \\
\text { or Tuber (15 g), Taraxaci Herba (15 g), Chrysanthemi Indici Flos (15 g), } \\
\text { Pseudostellariae Radix (6 g), Schisandrae Chinensis Fructus (6 g) }\end{array}$ & $100 \mathrm{ml}$ & TGF- $\beta 1 \downarrow$ & $\mathrm{RP}$ & $\begin{array}{l}\text { (Chen et al., } \\
\text { 2017) }\end{array}$ \\
\hline Xue Bi Jing Injection & $\begin{array}{l}\text { Carthami Flos, Paeoniae Radix Rubra, Chuanxiong Rhizoma, } \\
\text { Salviae Miltiorrhizae Radix et Rhizoma, Angelicae Sinensis Radix }\end{array}$ & $100 \mathrm{ml}$ & $\begin{array}{l}\text { HMGB } 1 \downarrow ; \text { TGF- } \beta 1 \downarrow ; \text { IL-6 } \\
\downarrow ; \text { TNF- } \alpha \downarrow\end{array}$ & $\mathrm{RIPI}$ & (Tan et al., 2014) \\
\hline $\begin{array}{l}\text { Compound Ku Shen } \\
\text { Injection }\end{array}$ & Sophorae Flavescentis Radix, Smilacis Glabrate Rhizoma & $30 \mathrm{ml}$ & $\begin{array}{l}\text { TGF- } \beta 1 \downarrow \text {; fibronectin } \downarrow \text {; } \\
\text { TNF- } \alpha \downarrow ; \text { CTGF } \downarrow\end{array}$ & RIPI RP & (Luo et al., 2015) \\
\hline
\end{tabular}

CTGF, connective tissue growth factor; EMT, epithelial-mesenchymal transition; ERK, extracellular signal-regulated (protein) kinase; ET-1, endothelin-1; FEV1, forced expiratory volume in $1 \mathrm{~s}$; FVC, forced vital capacity; GSK, glycogen synthase kinase; HMGB1, high mobility group protein B 1; HP, hydroxyproline; IFN- $\gamma$, interferon- $\gamma ;$ IL-1, interleukin-1; IL-10, interleukin-10; IL-4, interleukin-4; IL-6, interleukin-6; LDH, lactate dehydrogenase; MDA, malondialdehyde; MMP, matrix metalloproteinase-9; RIPF, radiation-induced pulmonary fibrosis; RIPI, radiation-induced pulmonary injury; ROS, reactive oxygen species; RP, radiation pneumonitis; SOD, superoxide dismutase; SP-A, surfactant protein a; TGF- $\beta 1$, transforming growth factor; TIMP-1, tissue inhibitor of metalloproteinase-1; TNF- $\alpha$, tumor necrosis factor- $\alpha$; VC, vital capacity; NA, not available; $\uparrow$, up-regulation or activation; $\downarrow$, down-regulation or inactivation. 
TABLE 2 | Species list of CMs for anti-RIPI.

\begin{tabular}{|c|c|c|c|c|c|}
\hline $\begin{array}{l}\text { Chinese } \\
\text { name }\end{array}$ & English name & $\begin{array}{l}\text { Latin name in the Chinese } \\
\text { Pharmacopeia (Version 2015) }\end{array}$ & $\begin{array}{l}\text { Accepted/Synonym name in the } \\
\text { Plant List }\end{array}$ & $\begin{array}{c}\text { Frequency } \\
(\%)\end{array}$ & Potential toxicity \\
\hline 黄芪 & Astragali Radix & $\begin{array}{l}\text { Astragalus membranaceus (Fisch). Bge. } \\
\text { var. mongholicus (Bge). Hsiao } \\
\text { Astragalus membranaceus (Fisch).Bge. }\end{array}$ & $\begin{array}{l}\text { Astragalus trimestris L. } \\
\text { Astragalus mongholicus Bunge }\end{array}$ & 8.47 & \\
\hline 麦冬 & Ophiopogonis Radix & Ophiopogon japonicus (L. f) Ker-GawL & $\begin{array}{l}\text { Ophiopogon japonicus (Thunb). Ker } \\
\text { Gawl. }\end{array}$ & 6.78 & \\
\hline 甘草 & $\begin{array}{l}\text { Glycyrrhizae Radix et } \\
\text { Rhizoma }\end{array}$ & $\begin{array}{l}\text { Glycyrrhiza uralensis Fisch. } \\
\text { Glycyrrhiza inflate Bat. } \\
\text { Glycyrrhiza glabra L. }\end{array}$ & $\begin{array}{l}\text { Glycyrrhiza uralensis Fisch. } \\
\text { Glycyrrhiza inflate Batalin } \\
\text { Glycyrrhiza glabra L. }\end{array}$ & 5.08 & $\begin{array}{l}\text { Hypertension and } \\
\text { hypokalemic-induced } \\
\text { secondary disorders } \\
\text { (Nazari et al., 2017) }\end{array}$ \\
\hline 赤苻 & Paeoniae Radix Rubra & $\begin{array}{l}\text { Paeonia lactiflora PalL } \\
\text { Paeonia veitchii Lynch }\end{array}$ & $\begin{array}{l}\text { Paeonia lactiflora Pall. } \\
\text { Paeonia veitchii Lynch }\end{array}$ & 5.08 & \\
\hline 夏枯草 & Prunellae spica & Prunella vulgaris $\mathrm{L}$. & Prunella vulgaris L. & 5.08 & \\
\hline 当归 & Angelicae Sinensis Radix & Angelica sinensis (Oliv). Diels & Angelica sinensis (Oliv). Diels & 3.39 & \\
\hline 枇杷叶 & Eriobotrya folium & Eriobotrya japonica (Thunb). Lindl. & Eriobotrya japonica (Thunb). Lindl. & 3.39 & \\
\hline 连翘 & Forsythiae Fructus & Forsythia suspensa (Thunb). V ahl & Forsythia suspensa (Thunb). Vahl & 3.39 & \\
\hline 石膏 & a Gypsum $\left(\mathrm{CaSO}_{4} \bullet 2 \mathrm{H}_{2} \mathrm{O}\right)$ & & NA & 3.39 & \\
\hline 金银花 & Lonicerae Japonicae Flos & Lonicera japonica Thunb. & Lonicera japonica Thunb. & 3.39 & \\
\hline 牡丹皮 & Moutan cortex & Paeonia suffruticosa Andr. & Paeonia $\times$ suffruticosa Andrews & 3.39 & \\
\hline 太子参 & Pseudostellariae Radix & $\begin{array}{l}\text { Pseudostellaria heterophylla (Miq). Pax } \\
\text { ex Pax et Hoffm. }\end{array}$ & Pseudostellaria heterophylla (Miq). Pax & 3.39 & \\
\hline 丹参 & $\begin{array}{l}\text { Salviae Miltiorrhizae Radix et } \\
\text { Rhizoma }\end{array}$ & Salvia miltiorrhiza Bge. & Salvia miltiorrhiza Bunge & 3.39 & \\
\hline 苦杏仁 & Armeniacae semen amarum & $\begin{array}{l}\text { Prunus armeniaca L. var. ansu Maxim. } \\
\text { Prunus sibirica L. } \\
\text { Prunus mandshurica (Maxim). Koehne } \\
\text { Prunus armeniaca L. }\end{array}$ & $\begin{array}{l}\text { Prunus armeniaca L. } \\
\text { Prunus sibirica L. } \\
\text { Prunus mandshurica (Maxim). Koehne } \\
\text { Prunus mume (Siebold) Siebold \& } \\
\text { Zucc. }\end{array}$ & 1.69 & $\begin{array}{l}\text { \#Nausea, vomiting, diarrhea, } \\
\text { dizziness, weakness, mental } \\
\text { confusion, and convulsions } \\
\text { followed by terminal coma } \\
\text { and literally death (Chaouali } \\
\text { et al., 2013) }\end{array}$ \\
\hline 阿胶 & ${ }^{\mathrm{b}}$ Asini corii colla & Equus asinm L. & NA & 1.69 & \\
\hline 紫苑 & Asteris Radix et Rhizoma & Aster tataricus L. f. & Aster tataricus L.f. & 1.69 & \\
\hline 红花 & Carthami Flos & Carthamus tinctorius L. & Carthamus tinctorius L. & 1.69 & \\
\hline 野菊花 & Chrysanthemi indici flos & Chrysanthemum indicum L. & Chrysanthemum indicum L. & 1.69 & \\
\hline 川芎 & Chuanxiong Rhizoma & Ligusticum chuanxiong Hort. & Ligusticum striatum DC. & 1.69 & \\
\hline 党参 & Codonopsis Radix & $\begin{array}{l}\text { Codonopsis pilosula (Franch). Nannf. } \\
\text { Codonopsis pilosula Nannf. var. } \\
\text { modesta (Nannf). L. T. Shen } \\
\text { Codonopsis tangshen Oliv. }\end{array}$ & $\begin{array}{l}\text { Codonopsis pilosula (Franch). Nannf. } \\
\text { Codonopsis pilosula (Franch). Nannf. } \\
\text { Codonopsis tangshen Oliv. }\end{array}$ & 1.69 & \\
\hline 山慈菇 & $\begin{array}{l}\text { Cremastrae Pseudobulbs } \\
\text { Pleiones Pseudobulbus }\end{array}$ & $\begin{array}{l}\text { Cremastra appendiculata (D. Don) } \\
\text { Makino } \\
\text { Pleione bulbocodioides (Franch). Rolfe } \\
\text { Pleione yunnanensis Rolfe }\end{array}$ & $\begin{array}{l}\text { Cremastra appendiculata (D. Don) } \\
\text { Makino } \\
\text { Pleione bulbocodioides (Franch). Rolfe } \\
\text { Pleione yunnanensis (Rolfe) Rolfe }\end{array}$ & 1.69 & \\
\hline 姜黄 & Curcumae Longae rhizoma & Curcuma longa L. & Curcuma longa L. & 1.69 & \\
\hline 郁金 & Curcumae radix & $\begin{array}{l}\text { Curcuma wenyujin Y. H. Chen et C. Ling } \\
\text { Curcuma longa L. } \\
\text { Curcuma kwangsiensis S. G. Lee et C. } \\
\text { F. Liang } \\
\text { Curcuma phaeocaulis Val. }\end{array}$ & $\begin{array}{l}\text { Curcuma aromatica Salisb. } \\
\text { Curcuma longa L. } \\
\text { Curcuma kwangsiensis S.G.Lee \& } \\
\text { C.F.Liang } \\
\text { Curcuma phaeocaulis Valeton }\end{array}$ & 1.69 & \\
\hline 葶芳子 & $\begin{array}{l}\text { Descurainiae semen lepidii } \\
\text { semen }\end{array}$ & $\begin{array}{l}\text { Descurainia sophia (L). Webb. ex Prantl. } \\
\text { Lepidium apetalum Wild }\end{array}$ & $\begin{array}{l}\text { Descurainia sophia (L). Webb ex Prantl } \\
\text { Lepidium apetalum Wild. }\end{array}$ & 1.69 & \\
\hline 青天葵 & Ford Nervilia Herb or Tuber & Nervilia fordii (Hance) Schltr. & Nervilia fordii (Hance) Schltr. & 1.69 & \\
\hline 川贝母 & Fritillariae cirrhosae bulbus & $\begin{array}{l}\text { Fritillaria cirrhosa D. Don } \\
\text { Fritillaria unibracteata Hsiao et K. C. Hsia }\end{array}$ & $\begin{array}{l}\text { Fritillaria cirrhosa D. Don } \\
\text { Fritillaria unibracteata P.K.Hsiao \& } \\
\text { K.C.Hsia }\end{array}$ & 1.69 & \\
\hline & & $\begin{array}{l}\text { Fritillaria przewalskii Maxim. } \\
\text { Fritillaria delavayi Franch. } \\
\text { Fritillaria taipaiensis P. Y. Li } \\
\text { Fritillaria unibracteata Hsiao et K. C. Hsia } \\
\text { var wabuensis (S. Y. Tang et S. C. Yue) } \\
\text { Z. D. Liu, S. Wang et S. C. Chen }\end{array}$ & $\begin{array}{l}\text { Fritillaria przewalskii Maxim. ex Batalin } \\
\text { Fritillaria delavayi Franch. } \\
\text { Fritillaria taipaiensis P.Y.Li } \\
\text { Fritillaria unibracteata P.K.Hsiao \& } \\
\text { K.C.Hsia }\end{array}$ & & \\
\hline
\end{tabular}


TABLE 2 | Continued

\begin{tabular}{|c|c|c|c|c|c|}
\hline $\begin{array}{l}\text { Chinese } \\
\text { name }\end{array}$ & English name & $\begin{array}{l}\text { Latin name in the Chinese } \\
\text { Pharmacopeia (Version 2015) }\end{array}$ & $\begin{array}{l}\text { Accepted/Synonym name in the } \\
\text { Plant List }\end{array}$ & $\begin{array}{l}\text { Frequency } \\
\text { (\%) }\end{array}$ & Potential toxicity \\
\hline 人参 & Ginseng Radix et Rhizoma & Panax ginseng C. A. Mey. & Panax ginseng C.A.Mey. & 1.69 & $\begin{array}{l}\text { Potentiates imatinib-induced } \\
\text { hepatotoxicity (Bilgi et al., } \\
\text { 2010) }\end{array}$ \\
\hline 枸杞子 & Lycii Fructus & Lycium barbarum L. & Lycium barbarum L. & 1.69 & \\
\hline 薄荷 & Menthae Haplocalycis Herba & Mentha haplocalyx Briq. & Mentha canadensis L. & 1.69 & \\
\hline 桑叶 & Mori folium & Morus alba L. & Morus alba L. & 1.69 & \\
\hline 白苟 & Paeoniae radix alba & Paeonia lactiflora Pall. & Paeonia lactiflora Pall. & 1.69 & \\
\hline 桃仁 & Persicae semen & Prunus persica (L). Batsch & Prunus persica (L). Batsch & 1.69 & \\
\hline & & Prunus davidiana (Carr). Franch. & Prunus davidiana (Carrière) Franch. & & \\
\hline 熟地黄 & $\begin{array}{l}\text { Rehmanniae Radix } \\
\text { Praeparata }\end{array}$ & Rehmannia glutinosa Libosch. & Rehmannia glutinosa (Gaertn). DC. & 1.69 & \\
\hline 红景天 & $\begin{array}{l}\text { Rhodiola Crenulatae Radix } \\
\text { et Rhizoma }\end{array}$ & $\begin{array}{l}\text { Rhodiola crenulata (Hook. f. et Thoms). } \\
\text { H. Ohba }\end{array}$ & $\begin{array}{l}\text { Sedum crenulatum Hook.f. \& } \\
\text { Thomson }\end{array}$ & 1.69 & \\
\hline 五味子 & $\begin{array}{l}\text { Schisandrae Chinensis } \\
\text { Fructus }\end{array}$ & Schisandra chinensis (Turcz). Baill & Schisandra chinensis (Turcz). Baill. & 1.69 & \\
\hline 玄参 & Scrophulariae radix & Scrophularia ningpoensis Hemsl & Scrophularia ningpoensis Hemsl. & 1.69 & \\
\hline 芝麻 & Sesame & Sesamum indicum L. & Sesamum indicum L. & 1.69 & \\
\hline 蒲公英 & Taraxaci herba & $\begin{array}{l}\text { Taraxacum mongolicum Hand Mazz. } \\
\text { Taraxacum borealisinense Kitam. }\end{array}$ & $\begin{array}{l}\text { Taraxacum mongolicum Hand.-Mazz. } \\
\text { Taraxacum sinicum Kitag. }\end{array}$ & 1.69 & \\
\hline
\end{tabular}

\#The identified toxic Chinese medicines according to the Chinese Pharmacopeia (Version 2015). ${ }^{a}$ Mineral; b Animal parts; NA: not available.
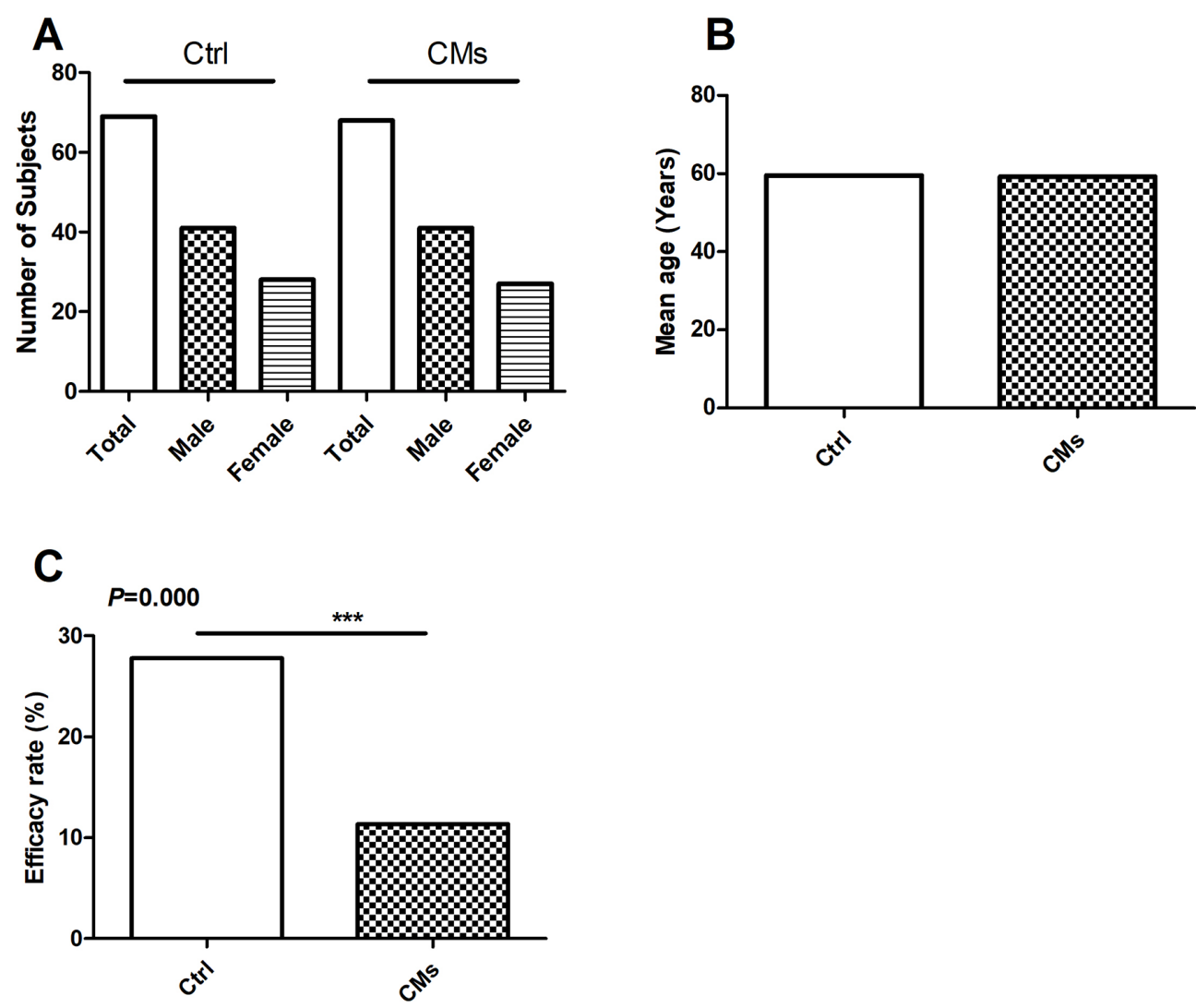

FIGURE 2 | Efficacy of Chinese Medicines (CMs) for preventing radiation-induced pulmonary injury (RIPI) in patients in the clinical studies. (A) The number and gender of patient comparison between the control and the CM-treated groups. (B) The average age of patient comparison between the control and the CM-treated groups. (C) The RIPI occurrence rate of the combination treatment of CMs with Western medical strategies vs. the Western medical strategies alone (Ctrl). ${ }^{\star \star \star} P<0.001$ 

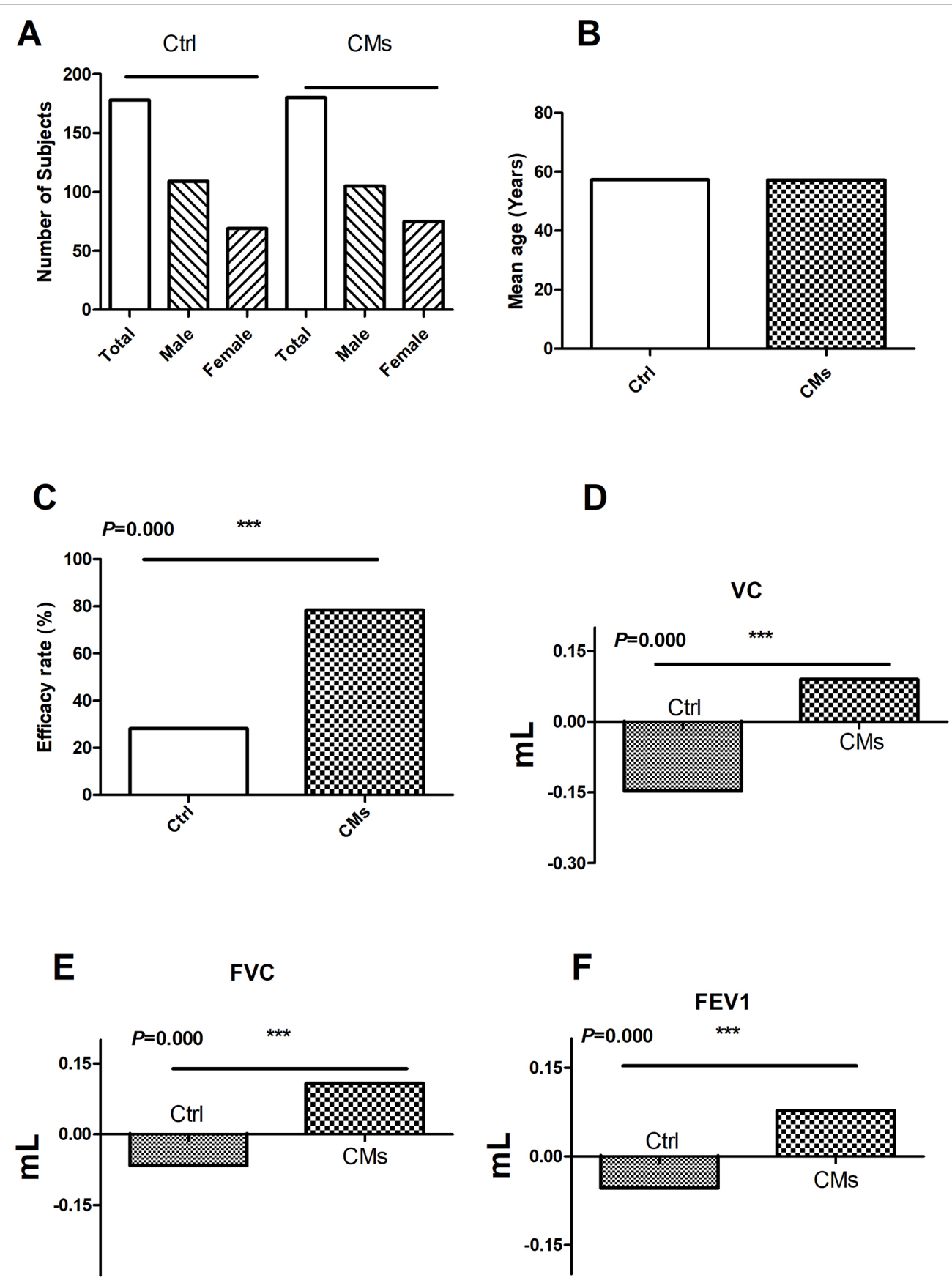

FIGURE 3 | Efficacy of CMs for treating RIPI patients in the clinical studies. (A) The number and gender of patient comparison between the control and the CM-treated groups. (B) The age of patient comparison between the control and the CM-treated groups. (C) Overall efficacy comparison between the control and the CM-treated groups. (D) The comparison of VC changes before and after CM treatment. (E) The comparison of FVC changes before and after CM treatment. (F) The comparison of FEV1 changes before and after CM treatment. Ctrl: the Western medical strategies alone; CMs: the CMs or CMs combined with Western medical strategies. ${ }^{\star \star \star} P<0.001$.

\section{Overall Efficacy of CMs for Treating RIPI}

In the three clinical studies with efficacy data, the treatment groups were $\mathrm{CMs}$ alone or combined with Western medicine. The control groups were Western medicine. The results showed that CMs alone and CMs combined with Western medical treatment were more effective than control groups $(78.33 \%$ vs. $28.09 \%)(P<$ 0.001 , Figure 3).

Furthermore, the change in pulmonary function was investigated in two studies. In total, 120 patients (74 males and 46 females) were treated with $\mathrm{CMs}$ or CMs combined with Western medical 
treatment. Compared with the control groups (Ctrl, 120 patients including 77 males and 43 females), CMs and CMs combined with Western medical treatment were more useful for the improvement of the VC, FVC, and FEV1, indicating that CMs or CMs combined with Western medical treatment were more effective in improving the impaired lung function (Figure 3).

\section{CMs: Commonly Used Families, Traditional Action Classification, and Frequency of Usage}

As CMs for RIPI were used according to their traditional property, it is necessary to explore the relationship between pharmacological effects and traditional function, as well as CM species. We firstly summarized CMs according to traditional action classification (Chen et al., 2017). However, interestingly, only 5 out of 17 current categories of CMs were used. The order according to the frequency from high to low was as follows: tonics (TON, 34.21\%); heat-clearing medicines (HCM, 31.58\%); expectorants, antitussives, and antiasthmatics (EAA, 15.79\%); blood invigorating and stasis resolving medicines (BISRM, 15.79\%); and astringent medicines (AST, 2.63\%) (Figure 4). The top five most frequently used CMs were Astragali radix (with a frequency of $8.47 \%$ ), Ophiopogonis radix (with a frequency of $6.78 \%$ ), Glycyrrhizae radix et rhizome (with a frequency of $5.08 \%$ ), Paeoniae Radix Rubra (with a frequency of 5.08\%), and Prunellae spica (with a frequency of 5.08\%) (Table 2).

\section{DISCUSSION}

Thoracic radiotherapy is the mainstay for the treatment of cancer diseases. However, RIPI is the dose-limiting factor precluding a curative therapy in some cases (Huang et al., 2017). Although several treatment regimens may alleviate RIPI, the therapeutic

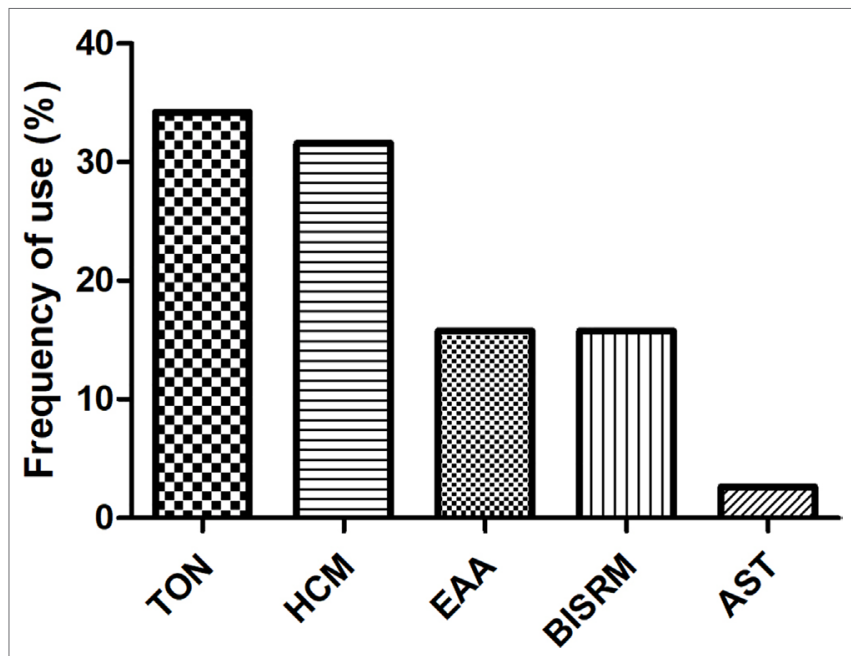

FIGURE 4 | Usage frequency of CMs on RIPI. The usage frequency of traditional action classification of CMs on RIPI. TON, tonics; HCM, heat-clearing medicines; EAA, expectorants, antitussives, and antiasthmatics; BISRM, blood invigorating and stasis resolving medicines AST, astringent medicines. effects are often unsatisfactory, and these medicines also induce some new side effects (Giridhar et al., 2015). Thus, it is an urgent issue to seek novel drugs for RIPI without serious side effects. CMs have a very long history of curing patients with lung diseases, in which some effective medicines may be found for the prevention and treatment of RIPI (Deng et al., 2017). In this review, we retrieved the most recent publications in the last 10 years, from 2007 to 2017, in different online databases to provide comprehensive insight into the efficacy of CMs on RIPI. We found that eight studies met our criteria. Some CMs were frequently used. In total, eight formulae were used in the reviewed literature. The indices and parameters of pulmonary function were summarized and analyzed to investigate the therapeutic effects of CMs on RIPI quantitatively. The total RIPI occurrence in the CM-preventing groups was significantly lower than that of the control groups $(11.37 \%$ vs. $27.78 \%)(P<0.001)$, while the treatment efficacy of CMs was significantly higher than that in the control group (78.33 vs. $28.09 \%, P<0.001)$. Our results might be helpful to discover the most effective CMs for treating RIPI if the high-quality studies would be conducted.

The underlying mechanisms of CMs on RIPI seem to be complicated. In addition to the well-known inflammatory and fibrotic factors, other factors, such as oxidative response factors and immune cytokines, were also involved. In this review, CMs may be associated with enhancing anti-oxidation, anti-inflammation, and anti-fibrosis properties, and improving immune function. As to the anti-oxidation property, Shen Fu Injection reduced ROS (Bi and Sun, 2015). For anti-inflammation, CMs alleviated RIPI by reducing inflammatory factors such as IL-1, IL-4, IL-6, IL-10, high mobility group protein B1 (HMGB1), prostaglandin (PGE2), and tumor necrosis factor- $\alpha$ (TNF- $\alpha$ ) (Tables 1 and 2). Regarding enhancing the immune function, Qing Fei Yang Yin Huo Xue Fang activated NK cells. For pulmonary fibrosis, Mai Men Dong Decoction-2 reduced epithelial-mesenchymal transition (EMT) by activation of TGF- $\beta$ (Liu et al., 2016); Scutellariae Radix for EMT may be associated with its active component, baicalin, which inhibited extracellular regulated protein kinases (ERK)/

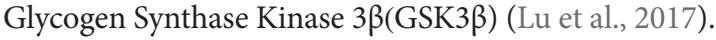

To unveil the relationship between the pharmacological effects and the traditional applications of CMs, the frequency of the species was summarized in Table 2 , and CM category according to their traditional applications was analyzed in Figure 4. All botanical species were checked using the Chinese Pharmacopeia (Version 2015) and the online database of the Plant List (Table 2). For the $38 \mathrm{CMs}$ in this review, 36 botanic families, one animal part, and one mineral were used. Interestingly, only five categories of CMs were used for RIPI. In fact, there are up to 17 categories of CMs in use to treat various diseases according to their traditional applications, including exterior-releasing medicines; heat-clearing medicines; medicines that drain downwards; medicines that expel wind and damp; damp-resolving medicines; damp-draining medicines; medicines that warm the interior; Qi-regulating medicines; digestant medicines; medicines that stop bleeding; blood invigorating and stasis resolving medicines; expectorants, antitussives and antiasthmatics; medicines that quiet the spirit; liver-pacifying and wind-extinguishing medicines; resuscitative medicines; tonics; and astringent 
medicines (Chen, 2017). The reviewed five categories might be closely associated with their pharmacological actions for RIPI. The first class was tonics (e.g., Astragali Radix, Ophiopogonis Radix, and Glycyrrhizae Radix et Rhizoma). Tonics could enhance immune function, which indicates that tonics may attenuate the symptoms by enhancing resistance to RIPI. The second class was heat-clearing medicines (e.g., Paeoniae Radix Rubra and Prunellae Spica). The main pharmacological effects of heat-clearing medicines are anti-inflammation, anti-pathogenic microorganism, adjusting immune function, anti-pyretic effects, and so on. The third class was the expectorants, antitussives, and antiasthmatics (e.g., Eriobotryae Folium, Armeniacae Semen Amarum, and Asteris Radix et Rhizoma), which could dispel phlegm, inhibit coughing, and exert an anti-inflammation effect, and these CMs respond by targeting pneumonitis and pulmonary fibrosis. As for the blood-invigorating and stasis-resolving medicines (e.g., Salviae Miltiorrhizae Radix et Rhizome), it may treat RIPI by anti-oxidative and anti-inflammation (Peng et al., 2019; Yang et al., 2019). The fifth and last class was astringent medicines (Schisandrae chinensis fructus), which could exert cough suppression, anti-fibrosis, and immune regulation. This may be its potential use for RIPI (Chen, 2017; Zhai et al., 2014). Interestingly, the most frequently used species were tonics, Astragali Radix (with a frequency of $8.47 \%$ ), and Ophiopogonis Radix (with a frequency of 6.78\%), indicating that enhancing the immune function is more critical than anti-inflammation in RIPI (Table 2).

However, further high-quality investigations should be warranted. The research quality with regards to repeatability and standardization is vital for CMs. The diversity of CM species is a limitation in this review, which may affect the quality of the studies. Although we checked all the CMs with the Chinese Pharmacopeia (Version 2015) and the Plant List (www.theplantlist.org) in this study (Table 2), it was still hard to identify the detail species of the used CMs. For the most CMs, there are more than one source for medicinal use. For example, according to the Chinese Pharmacopeia (Version 2015), there are three sources for Glycyrrhizae Radix et Rhizoma, Glycyrrhiza uralensis Fisch. (accepted name in the Plant List), Glycyrrhiza inflate Bat. (accepted name in the Plant List), and Glycyrrhiza glabra L. (accepted name in the Plant List). These three different species may have different components, which might result in different effects. Actually, $11 \mathrm{CMs}$ had more than one species in this review (28.95\% out of the total CMs).

Furthermore, because of the similar Chinese names but very different sources, the species of CMs that were not given or could not be determined were excluded in this review. The paper only describing Sha Shen (沙参) was not considered in this review because there are two different resources of Sha Shen, where one is named Bei Sha Shen (Glehniae Radix in English, 北沙 参 or North Sha Shen), which is the root of Glehnia littoralis Fr. Schmidt ex Miq. (Family: Umbelliferae) (Committee of Chinese Pharmacopeia, 2015a), while the other is named Nan Sha Shen (Adenophorae Radix in English, 南沙参 or South Sha Shen), which is the root of Adenophora tetraphylla (Thunb). Fisch or Adenophora stricta Miq. (Family: Campanulaceae) (Committee of Chinese Pharmacopeia, 2015b). This means that they share similar Chinese names but are different species, which may result in different pharmacological/toxicological effects. The other similar reason for the standardization of CM research is to verify the process of CM preparation and formulae components. Otherwise, the active components and pharmacological effects would result in differences and confusion. Therefore, the factors that would decrease the quality of research were excluded.

In addition, though the prevention and treatment efficacy of CMs on RIPI were promising, little details of ethical protocols were described in the reviewed studies. This is a very important aspect for patient safety in clinical trials. With regards to publications, 191 out of 199 were excluded due to the low quality of the studies, including 20 articles with neither any ethical approval nor patients' agreement or signing informed consents. Only three clinical studies investigated the VC, FVC, and FEV1 in the treatment cases, the most important indices for pulmonary function.

Another critical issue of CMs is their toxicity and side effects. Herbal medicines have attracted more attention since aristolochic acid-induced nephropathy was reported (Cosyns, 2003). Though there was no toxicity reported in this review, some CMs have been reported to induce irritation (Zhu et al., 2012; Zhong et al., 2006) and be toxic in the endocrine system (Arbo et al., 2009), reproductive system (Tian et al., 2009), liver (Bilgi et al., 2010; Zhang et al., 2009), digestive system, nervous system (Xu et al., 2018; Chaouali et al., 2013), etc. The potential toxic CMs are listed in Table 2, in which herb-induced liver injury (HILI) can be assessed using the CIOMS/RUCAM scale (Fu et al., 2018). Furthermore, according to the Chinese Pharmacopeia, Armeniacae semen amarum was identified as "slightly toxic" (Table 2). Notably, this also includes that they would be "very toxic," "toxic," and "slightly toxic" if they had been used irrationally. Unfortunately, the maximal tolerance and LD50 are not standardized for many CMs as in Western medicine. Regarding this study, the papers mentioned the safety of CMs in which there were no particular methods, designs, and further index results for an LD50 investigation. Nevertheless, we still would like to sensitize the medical staff to the toxicity of CMs.

\section{CONCLUSION}

In conclusion, although CMs might play a promising role in RIPI prevention and treatment, there is still a long way to go for CMs on RIPI. Further high-quality investigations in species, pharmacological effects and underlying mechanisms, and ethical and toxicological aspects are warranted.

\section{AUTHOR CONTRIBUTIONS}

XBW, XHW, and FC designed the study. YD, YCL, HL, and MLiu retrieved the literature. YD and YCL screened and doublechecked the literature; YD and XBW analyzed the data and wrote the manuscript. MLi and YL polished the manuscript. All authors read and approved the final version. 


\section{FUNDING}

The study was financially supported by the National Natural Science Foundation of China (81874356); the Hubei Provincial Natural Science Foundation (2018CFC874); the Young Scientist Innovation Team Project of Hubei Colleges (T201510); the Hubei Province Health and Family Planning Scientific Research Project (WJ2017Z023); the Open Project of Hubei Key Laboratory of Wudang Local Chinese Medicine Research, Hubei University of Medicine (WDCM2018002);

\section{REFERENCES}

Abid, S. H., Malhotra, V., and Perry, M. C. (2001). Radiation-induced and chemotherapy-induced pulmonary injury. Curr. Opin. Oncol. 13, 242-248. doi: 10.1097/00001622-200107000-00006

Arbo, M. D., Franco, M. T., Larentis, E. R., Garcia, S. C., Sebben, V. C., Leal, M. B., et al. (2009). Screening for in vivo (anti)estrogenic activity of ephedrine and p-synephrine and their natural sources Ephedra sinica Stapf. (Ephedraceae), and Citrus aurantium L. (Rutaceae) in rats. Arch. Toxicol. 83, 95-99. doi: 10.1007/s00204-008-0324-8

$\mathrm{Bi}$, J., and Sun, Y. (2015). Investigation of Shen fu injection on radioactive lung injury of the patient with thoracic tumor radiotherapy. He Bei Zhong Yi 37, 422-424. doi: 10.3969/j.issn.1002-2619.2015.03.037

Bilgi, N., Bell, K., Ananthakrishnan, A. N., and Atallah, E. (2010). Imatinib and Panax ginseng: a potential interaction resulting in liver toxicity. Ann. Pharmacother. 44, 926-928. doi: 10.1345/aph.1M715

Cao, K., Lei, X., Liu, H., Zhao, H., Guo, J., Chen, Y., et al. (2017). Polydatin alleviated radiation-induced lung injury through activation of Sirt3 and inhibition of epithelial-mesenchymal transition. J. Cell. Mol. Med. 21, 32643276. doi: 10.1111/jcmm.13230

Chen, C. (2017). Pharmacology of Chinese Materia Medica. 1st edition. Beijing: Zhong Guo Zhong Yi Yao Chu Ban She.

Chen, S., Chou, T., Wang, Y., He, F., Yu, T., Xiang, T., et al. (2017). Clinical study of Modified Wu Wei Xiao Du Decoction in the prevention and treatment of radiation pneumonia in patients with non-small cell lung cancer after chemotherapy. Shang Hai Zhong Yi Yao Za Zhi 51, 37-40. doi: 10.16305/j.1007-1334.2017.11.011

Chaouali, N., Gana, I., Dorra, A., Khelifi, F., Nouioui, A., Masri, W., et al. (2013). Potential toxic levels of cyanide in almonds (Prunus amygdalus), apricot kernels (Prunus armeniaca), and almond syrup. ISRN Toxicol. 2013, 610648. doi: $10.1155 / 2013 / 610648$

Committee of Chinese Pharmacopeia (2015a). Chinese Pharmacopeia. 1st edition. Beijing: Zhong Guo Yi Yao Ke Ji Chu Ban She, 100.

Committee of Chinese Pharmacopeia (2015b). Chinese Pharmacopeia. 1st edition. Beijing: Zhong Guo Yi Yao Ke Ji Chu Ban She, 244-245.

Cosyns, J.P. (2003). Aristolochic acid and Chinese herbs nephropathy: a review of the evidence to date. Drug Saf. 26, 33-48. doi: 10.2165/00002018-200326010-00004

Demirel, C., Kilciksiz, S. C., Gurgul, S., Erdal, N., Yigit, S., Tamer, L., et al. (2016). Inhibition of radiation-induced oxidative damage in the lung tissue: may acetylsalicylic acid have a positive role? Inflammation 39, 158-165. doi: 10.1007/s10753-015-0234-x

Deng, B., Deng, C., and Cheng, Z. (2017). Chinese herbal extractions for relieving radiation induced lung injury: a systematic review and meta-analysis. Evid. Based Complement. Alternat. Med. 2017, 2141-2155. doi: 10.1155/2017/ 2141645

Enache, I., Noel, G., Mi, Y., Meyer, N., Pistea, C., Mennecier, B., et al. (2013). Impact of 3D conformal radiotherapy on lung function of patients with lung cancer: A prospective study. Respiration 86, 100-108. doi: 10.1159/000342371

Fu, B., Wang, N., Tan, H. Y., Li, S., Cheung, F., and Feng, Y. (2018). Multicomponent herbal products in the prevention and treatment of chemotherapyassociated toxicity and side effects: A review on experimental and clinical evidences. Front. Pharmacol. 9, 1394. doi: 10.3389/fphar.2018.01394 the Key Discipline Project of Hubei University of Medicine and the Foundation for Innovative Research Team of Hubei University of Medicine (2014CXG03, 2018YHKT01); and the Key Discipline Project of Hubei Province (2014XKJSXJ18).

\section{ACKNOWLEDGMENTS}

We would like to express thanks to Mr. Md Rezaul Karim for his English language revision.

Giridhar, P., Mallick, S., Rath, G. K., and Julka, P. K. (2015). Radiation induced lung injury: Prediction, assessment, and management. Asian Pac. J. Cancer Prev. 16, 2613-2617. doi: 10.7314/APJCP.2015.16.7.2613

Huang, Y., Zhang, W., Yu, F., and Gao, F. (2017). The cellular and molecular mechanism of radiation-induced lung injury. Med. Sci. Monit. 23, 3446-3450. doi: 10.12659/MSM.902353

Kaidar-Person, O., Marks, L. B., and Jones, E. L. (2018). Pentoxifylline and vitamin $\mathrm{E}$ for the treatment or prevention of radiation-induced fibrosis in patients with breast cancer. Breast J. 17, 1021-1024. doi: 10.1111/tbj.13044

Li, J., Wang, G., Li, Q., Zhao, L., and Sun, L. (2017). Effect of Qing Fei decoction on acute radiation-induced lung injury. Yun Nan Zhong Yi Zhong Yao Za Zhi 38, 58-60. doi: 10.3969/j.issn.1007-2349.2017.04.028

Liu, J., Wu, C., and Xiong, S. (2016). Mai Men Dong decoction in the prevention of radiation-induced lung injury and its effect on plasma TGF- $\beta 1$. Shi Yong $A i$ Zheng Za Zhi 31, 1947-1950. doi: 10.3969/j.issn.1001-5930.2016.12.010

Lu, J., Zhong, Y., Lin, Z., Lin, X., Chen, Z., Wu, X., et al. (2017). Baicalin alleviates radiation-induced epithelial-mesenchymal transition of primary type II alveolar epithelial cells via TGF-beta and ERK/GSK3beta signaling pathways. Biomed. Pharmacother. 95, 1219-1224. doi: 10.1016/j.biopha.2017.09.037

Nazari, S., Rameshrad, M., and Hosseinzadeh, H. (2017). Toxicological effects of Glycyrrhiza glabra (Licorice): A review. Phytother. Res. 31, 1635-1650. doi: $10.1002 /$ ptr.5893

Luo, X., Dai, Y., Dou, Y., Tian, W., Zhu, J., Li, S., et al. (2015). Clinical efficacy and safety of Fu fang Ku Shen injection on radiation-induced lung injury. Xian Dai Sheng Wu Yi Xue Jin Zhan 15, 3096-3099. doi: 10.13241/j.cnki,pmb.2015.16.023

Peng, L. Y., An, L., Sun, N. Y., Ma, Y., Zhang, X. W., Liu, W. H., et al. (2019). Salvia miltiorrhiza restrains reactive oxygen species-associated pulmonary fibrosis via targeting Nrf2-Nox4 redox balance. Am. J. Chin. Med., 1-19. doi: 10.1142/ S0192415X19500575

Ripa, L., Edman, K., Dearman, M., Edenro, G., Hendrickx, R., Ullah, V., et al. (2018). Discovery of a novel oral glucocorticoid receptor modulator (AZD9567) with improved side effect profile. J. Med. Chem. 61, 1785-1799. doi: 10.1021/acs.jmedchem.7b01690

Shi, Z., Sun, Y., Wang, J., Ji, G., Gu, Y., Lian, Y., et al. (2016). Clinical study on prevention and treatment of radiation pneumonia caused by radiotherapy of lung cancer with Qi Shen Yi Fei decoction. Zhong Yao Yao Li Yu Lin Chuang 32, 159-161. doi: 10.13412/j.cnki.zyyl.2016.03.043

Tan, B., Wu, X., Chen, Y., He, C., Wang, W., Liu, J., et al. (2014). Prevention effect of Xue Bi Jing injection on acute radiation-induced lung injury during radiation therapy of thoracic malignancies. Zhong Hua Zhong Liu Fang Zhi Za Zhi 21, 1986-1991. doi: 10.16.73/j.cnki.cjcpt.2014.24.012

Tian, X. Y., Cheung, L. M., Leung, K., Qi, C., Deng, B., Deng, P. X., et al. (2009) The effects of Scutellaria baicalensis extract on embryonic development in mice. Birth. Defects Res. B Dev. Reprod. Toxicol. 86, 79-84. doi: 10.1002/bdrb.20186

Tu, D., Hong, J., Zhang, Q., Yang, Q., Li, Y., and Guo, Y. (2015). The effect of Qing Re Huo Xue San Jie Chinese medicine on lung protection of patients with lung injury after radiotherapy and its effect on serum inflammatory factors. Shi Yong Ai Zheng Za Zhi 30, 1180-1183. doi: 10.3969/j.issn.1001-5930.2015.08.022

Tu, Y. (2016). Artemisinin-A gift from traditional Chinese medicine to the world (Nobel Lecture). Angew. Chem. Int. Ed. Engl. 55, 10210-10226. doi: 10.1002/ anie. 201601967 
Xia, D., Xi, L., Shen, W., Zhou, J., Shu, Z., and Hou, X. (2010). Investigation of Qing Zao Jiu Fei Recipe and Astragalus membranaceus on radioprotection of lung and expression of plasma transforming growth factor beta-1 and interleukin-1. Zhong Guo Shi Yan Fang Ji Xue Za Zhi 16, 240-243. doi: 10.13422/j.cnki.syfjx.2010.06.010

Xu, J. Y., Dai, C., Shan, J. J., Xie, T., Xie, H. H., Wang, M. M., et al. (2018). Determination of the effect of Pinellia ternata (Thunb). Breit. on nervous system development by proteomics. J. Ethnopharmacol. 213, 221-229. doi: 10.1016/j.jep.2017.11.014

Yang, J., Wang, B., Li, N., Zhou, W. and Zhen, Z. (2019). Salvia miltiorrhiza and Carthamus tinctorius extract prevents cardiac fibrosis and dysfunction after myocardial infarction by epigenetically inhibiting Smad3 expression. Evid. Based Complement Alternat. Med. 2019, 6479136. doi: 10.1155/2019/6479136

Zhai, H. Q., Hhang, J. R., Gao, M. C., Liu, Y., Zhang, S. F., Wang, X. H., et al. (2014). Comparative study between Ephedra sinica Stapf and Fructus Schisandrae Chinensis on ET-1 and 6-keto-prostaglandin F1alpha in rats with idiopathic pulmonary fibrosis. Genet. Mol. Res. 13, 3761-3771. doi: 10.4238/2014.May.13.3

Zhang, Y., Ke, W., Yang, J., Ma, A., and Yu, Z. (2009). The toxic activities of Arisaema erubescens and Nerium indicum mixed with Streptomycete against snails. Environ. Toxicol. Pharmacol. 27, 283-286. doi: 10.1016/j.etap.2008.11.003
Zhong, L. Y., Wu, H., Zhang, K. W., and Wang, Q. R. (2006). Study on irritation of calcium oxalate crystal in raw Pinellia ternata. Zhongguo Zhong Yao Za Zhi $31,1706-1710$

Zhou, C., and Chen, W. (2017). Curative effect of Bu Qi Yang Yin Qu Yu decoction on radioactive lung injury and influence on TGF- $\beta 1$, TNF- $\alpha$. Xian Dai Zhong Xi Yi Jie He Za Zhi 26, 2980-2983. doi: 10.3969/j. issn.1008-8849.2017.27.005

Zhu, F., Yu, H., Wu, H., Shi, R., Tao, W., and Qiu, Y. (2012). Correlation of Pinellia ternata agglutinin and Pinellia ternata raphides' toxicity. Zhongguo Zhong Yao Za Zhi 37, 1007-1011. doi: 10.4268/cjcmm20120729

Conflict of Interest Statement: The authors declare that the research was conducted in the absence of any commercial or financial relationships that could be construed as a potential conflict of interest.

Copyright (C) 2019 Ding, Liu, Li, Li, Li, Liu, Wang, Cao and Wang. This is an openaccess article distributed under the terms of the Creative Commons Attribution License (CC BY). The use, distribution or reproduction in other forums is permitted, provided the original author(s) and the copyright owner(s) are credited and that the original publication in this journal is cited, in accordance with accepted academic practice. No use, distribution or reproduction is permitted which does not comply with these terms. 